\title{
Physician Support for Non-Physician Advanced Practice Providers for Persons With Cardiopulmonary Disease
}

\author{
Shawna L Strickland, Sarah M Varekojis, Lynda T Goodfellow, John Wilgis, Susan W Hayashi, \\ Laura M Nolan, and George G Burton
}

\begin{abstract}
BACKGROUND: The use of non-physician advanced practice providers (NPAPP) has increased in the United States to offset shortages in the physician workforce. Yet there are still gaps in some locations where there is little to no access to quality health care. This study sought to identify whether physicians perceived a workforce gap and their level of interest in hiring an NPAPP with cardiopulmonary expertise to fill the perceived gap. METHODS: An American Association for Respiratory Care (AARC)-led workgroup surveyed 1,401 physicians in 6 different specialties. The survey instrument contained 32 closed-ended questions and 4 open-ended questions. RESULTS: $74 \%$ of the 1,401 physician respondents agreed or strongly agreed that there will be a future need for an NPAPP with cardiopulmonary expertise. Respondents from sleep, pediatrics, pulmonary, and critical care were most likely to indicate that there is a current need for an NPAPP. A majority of respondents perceived that the specialized NPAPP would improve efficiency and productivity $(\mathbf{7 4 \%})$, patient experience $(\mathbf{7 3} \%)$, and patient outcomes $(\mathbf{7 2} \%)$. Interest in adding this NPAPP did not increase when participants were told to presume authority for hiring, budget, and reimbursement. CONCLUSIONS: These results indicate that there is both a need for and an interest in hiring an NPAPP with cardiopulmonary expertise. Having an NPAPP would boost physician efficiency and productivity, improve the patient care experience, and provide benefits that other clinicians are not trained to provide to persons with cardiopulmonary disease. Results suggest there should be continued efforts to develop the NPAPP role to add value for physicians and patients alike. Key words: advanced practice; cardiac; cardiopulmonary disease; education; employment; nurse practitioner; physician; physician assistant; respiratory; respiratory therapy; staffing; training; workforce shortage. [Respir Care 2020;65(11):1702-1711. (C) 2020 Daedalus Enterprises]
\end{abstract}

\section{Introduction}

The Association of American Medical Colleges expects a shortage of up to 122,000 physicians in the United States by the year $2030 .{ }^{1}$ The use of non-physician advanced practice providers (NPAPPs), such as nurse practitioners and

Dr Strickland is affiliated with the American Association for Respiratory Care, Irving, Texas. Dr Varekojis is affiliated with The Ohio State University, Columbus, Ohio. Dr Goodfellow is affiliated with Georgia State University, Atlanta, Georgia. Mr Wilgis is affiliated with the Florida Hospital Association, Orlando, Florida. Dr Hayashi is affiliated with JBS International, Inc, North Bethesda, Maryland. Ms Nolan is affiliated with JBS International, Inc, North Bethesda, Maryland. Dr Burton is affiliated with Kettering College, Dayton, Ohio.

A version of this paper was presented at the AARC Summer Forum, held July 20-22, 2019, in Fort Lauderdale, Florida. physician assistants, has increased in the United States health system to offset shortages in the physician workforce and to reduce costs of medical services. ${ }^{2,3}$ In 2017, the American Association for Respiratory Care (AARC), the National Board for Respiratory Care (NBRC), and the Commission on Accreditation for Respiratory Care

\footnotetext{
Supplementary material related to this paper is available at http://www. rcjournal.com.

This work was supported by the American Association for Respiratory Care.

Dr Strickland is an employee of the American Association for Respiratory Care. Dr Goodfellow is a member of the Board of Directors of the American Association for Respiratory Care. Mr Wilgis was a member of Board of Directors of the American Association for Respiratory Care at the time of study. Dr Hayashi and Ms Nolan are employees of JBS International. Drs Varekojis and Burton have disclosed no conflicts of interest.
} 


\section{Physician Support for Advanced Practice Providers}

(CoARC) collaborated with JBS International, Inc., to complete an initial national needs assessment (phase 1) among physicians to determine if there was a need for an NPAPP with training specific to cardiopulmonary disease. The online survey from the phase 1 pilot study indicated that $70 \%$ of physicians indicated interest in hiring an NPAPP position, and approximately $20 \%$ expressed a strong need for the role. However, this phase 1 study had a relatively small sample size $(N=160)$ spread across 6 specialties. The overall margin of error was $\pm 7.75 \%$ at the $95 \%$ CI. Findings from this initial study indicated support for an NPAPP with cardiopulmonary expertise but did not contain sufficient responses to conduct subspecialty analysis or to identify the perceived impact of adding this position.

Therefore, the purpose of this study was to investigate where the need for the NPAPPs exists. In addition, we sought to identify the perceived impact of adding this position. This study focused on 4 research questions pertaining to an NPAPP specializing in care for patients with cardiopulmonary disease: (1) In which selected physician specialties is there a current or future workforce gap? (2) Among physicians who identify a workforce gap, where are they located geographically and is their practice setting inpatient or out-patient? (3) Assuming a mechanism for reimbursement is in place, which of the selected physician specialties are likely to hire an NPAPP? (4) What is the perceived impact of an NPAPP position?

\section{Methods}

In June 2018, an AARC-led workgroup in conjunction with JBS International conducted this phase 2 study to gain a deeper understanding of the trends observed in the phase 1 study. Phase 2 also examined where (geographically and by practice setting) the need exists. Similar to the pilot assessment, the phase 2 surveys were conducted online and by telephone. The survey instrument consisted of 36 questions related to NPAPP, 6 demographic questions, and 7 screening questions (Appendix A; see the supplementary materials at http://www.rcjournal.com). Participants were informed that it would take approximately $10-15 \mathrm{~min}$ to complete the survey. The Institutional Review Board at The Ohio State University approved the study.

\section{Instrument Development}

The survey was designed to answer the established research questions and to provide context for the responses.

Correspondence: Shawna L Strickland PhD RRT RRT-NPS RRT-ACCS AE-C FAARC, American Association for Respiratory Care, $9425 \mathrm{~N}$. MacArthur Blvd, Irving, TX 75063. E-mail: shawna.strickland@aarc.org.

DOI: $10.4187 /$ respcare. 07387

\section{QUICK LOOK}

\section{Current knowledge}

The use of non-physician advance practice providers (NPAPP) has increased in the U.S. to offset shortages in the physician workforce. However, there is a lack of entry-level NPAPP educational programs that prepare the provider to care for patients with cardiopulmonary disease.

\section{What this paper contributes to our knowledge}

This survey of physicians trained to work with patients with cardiopulmonary disease revealed agreement with a need for an NPAPP who specializes in the care of these patients and would likely hire them within their practice. Given increased acceptance of non-physician providers caring for patients across many specialty areas and the results of this study, this is an ideal time to introduce the role of an NPAPP into the routine care of patients with cardiopulmonary disease.

The survey questions were developed using content experts from the AARC, NBRC, and CoARC, with additional input from survey research instrument experts from JBS International. The original pilot study survey was used and questions that assessed perceived impact of adding an NPAPP specializing in care for patients with cardiopulmonary disease were added. Face validity of the survey was established via review by a volunteer committee of individuals from the AARC, NBRC, and CoARC.

\section{Selection Criteria}

The survey was conducted with a total of 1,401 respondents across 6 medical specialties specifically trained to work with persons who have cardiopulmonary disease. The medical specialties were selected based on input from the content experts and included allergy and immunology, anesthesiology, critical care, pediatrics, pulmonology, and sleep medicine. When physician participants specialized in $>1$ area, they were asked to indicate their primary role or specialty area (ie, where they spend the majority of their time) to allow respondents to be sorted into mutually exclusive categories. All physicians surveyed had been in postresidency practice for $>2 \mathrm{y}$ but $<40 \mathrm{y}$; they spent at least $25 \%$ of their time seeing and treating patients; and at least $20 \%$ of the patients in their care had cardiopulmonary disease.

Participant targets were quantified and monitored to ensure representative distribution of physician participants across the country based on U.S. Department of Health and Human Services regions ${ }^{4}$ and United States Census general 
Table 1. Participant Demographics

\begin{tabular}{|c|c|}
\hline Category & Respondents, $n(\%)$ \\
\hline \multicolumn{2}{|l|}{ Primary specialty } \\
\hline Allergy and immunology & $200(14.3)$ \\
\hline Anesthesiology & $200(14.3)$ \\
\hline Critical care & $200(14.3)$ \\
\hline Pediatrics & $400(28.5)$ \\
\hline Pulmonology & $200(14.3)$ \\
\hline Sleep specialist & $201(14.3)$ \\
\hline \multicolumn{2}{|l|}{ Post-residency practice experience } \\
\hline$<2 \mathrm{y}$ & $0(0)$ \\
\hline $2-10 y$ & $442(31.5)$ \\
\hline $11-15 y$ & $274(19.6)$ \\
\hline $16-20 y$ & $195(13.9)$ \\
\hline $21-30 y$ & $380(27.1)$ \\
\hline $31-40 y$ & $110(7.9)$ \\
\hline \multicolumn{2}{|l|}{ Practice setting } \\
\hline In-patient & $402(28.7)$ \\
\hline Out-patient & $522(37.2)$ \\
\hline Both in-patient and out-patient & $477(34.1)$ \\
\hline \multicolumn{2}{|l|}{ Practice setting location } \\
\hline Urban & $647(46.2)$ \\
\hline Suburban & $670(47.8)$ \\
\hline Rural & $84(6.0)$ \\
\hline \multicolumn{2}{|l|}{$\%$ of time spent treating patients } \\
\hline$<25 \%$ & $0(0)$ \\
\hline $25-49 \%$ & $19(1.4)$ \\
\hline $50-74 \%$ & $107(7.9)$ \\
\hline $75-100 \%$ & $1,275(91.0)$ \\
\hline \multicolumn{2}{|l|}{ Patients treated in 1 month } \\
\hline$<150$ & $342(24.4)$ \\
\hline $150-300$ & $633(45.2)$ \\
\hline $301+$ & $426(30.4)$ \\
\hline \multicolumn{2}{|l|}{$\begin{array}{l}\% \text { of patients with cardiopulmonary } \\
\text { disease }\end{array}$} \\
\hline$<20 \%$ & $0(0)$ \\
\hline $20-39 \%$ & $524(37.4)$ \\
\hline $40-59 \%$ & $388(27.7)$ \\
\hline $60-79 \%$ & $273(19.5)$ \\
\hline $80-100 \%$ & $216(15.4)$ \\
\hline \multicolumn{2}{|l|}{ Practice size } \\
\hline Solo practice & $107(7.6)$ \\
\hline Solo practice - shared facility & $21(1.5)$ \\
\hline Small group practice ( $<3$ physicians) & $123(8.8)$ \\
\hline Medium group practice ( $3-9$ physicians) & $463(33.1)$ \\
\hline Large group practice ( $\geq 10$ physicians) & $677(48.3)$ \\
\hline Other & $10(0.7)$ \\
\hline \multicolumn{2}{|l|}{ U.S. Department of Health and Human } \\
\hline \multicolumn{2}{|l|}{ Services Region } \\
\hline Region 1: Boston & $61(4.4)$ \\
\hline Region 2: New York & $196(14.0)$ \\
\hline Region 3: Philadelphia & $164(11.7)$ \\
\hline Region 4: Atlanta & $261(18.6)$ \\
\hline Region 5: Chicago & $236(16.9)$ \\
\hline Region 6: Dallas & $143(10.2)$ \\
\hline Region 7: Kansas City & $\begin{array}{l}56(4.0) \\
\text { (Continued) }\end{array}$ \\
\hline
\end{tabular}

Table 1. Continued

\begin{tabular}{lc}
\hline \multicolumn{1}{c}{ Category } & Respondents, $n(\%)$ \\
\hline Region 8: Denver & $39(2.8)$ \\
Region 9: San Francisco & $202(14.4)$ \\
Region 10: Seattle & $43(3.0)$ \\
\hline
\end{tabular}

population demographics. ${ }^{5}$ Similarly, respondents' practice setting type was also obtained from participants, although this was not part of the selection criteria.

Targeted specialties and sample size were determined based on a priori determination on a tolerable margin of error. Quota sampling was used to ensure proportional representation for medical specialties of interest. Participants were recruited from health care provider panels that use stringent quality control methods, such as requiring verification of professional credentials and in-depth profile questionnaires to ensure that respondents were accurately represented. Recruitment from the panels was passive; the potential participants were invited through the aforementioned panels and were directed to a participation link to opt into the survey to avoid respondents who were professional survey takers. The overall margin of error for this study was $\pm 2.62 \%$ at the $95 \% \mathrm{CI}$ and larger for subgroups. As it relates to specialties, the margin of error for pediatrics ( $n=400$ respondents) was $\pm 4.93 \%$, and the margin of error for any of the other five specialties ( $n=200$ respondents each) was $\pm 6.90 \%$.

\section{Survey Administration}

The survey was conducted by JBS International from May 24, 2018, to June 19, 2018, among a total of 1,401 practicing, board-certified or board eligible physicians in the United States. Some questions were randomized to reduce bias. Data collection was conducted via electronic survey and computer-assisted telephone interviews. Regardless of survey modality, all participants completed an identical survey instrument.

\section{Statistical Methods}

Descriptive data were reported as frequencies and percentages of the stated population. Chi-square analysis was conducted to determine if there were any associations between medical specialty or practice setting and assessment of current and future need for an NPAPP. The results were tested at alpha $=0.05$ using SPSS 25 (IBM, Armonk, New York).

\section{Results}

A total of 1,401 physicians completed the survey. Respondents identified themselves as one of 6 medical 


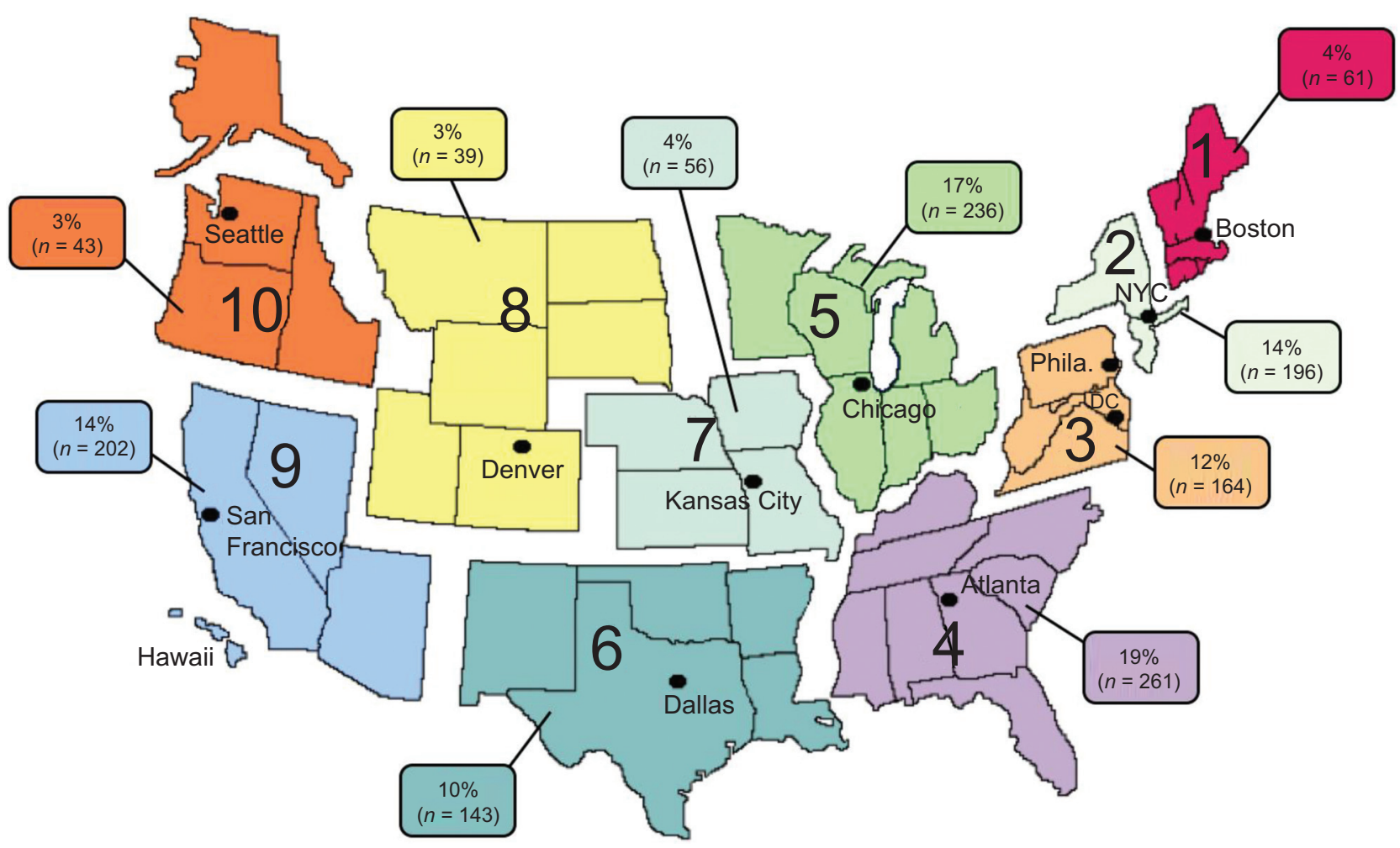

Figure 1. Respondents by geographic region.

specialties: allergy and immunology, anesthesia, critical care, pediatrics, pulmonology, or sleep medicine. Most respondents worked in urban or suburban areas, and the majority $(91.0 \%)$ spent at least $75 \%$ of their time in direct patient care. Practice setting was evenly represented, with $28.7 \%$ indicating in-patient only, $37.2 \%$ indicating outpatient only, and $34.1 \%$ practicing in both in-patient and out-patient settings. Demographic information is provided in Table 1 and geographic distribution of respondents is provided in Figure 1.

\section{Identification of the Workforce Gap for Cardiopulmonary Providers}

Physicians responded to questions about the current or future need for an NPAPP based on the understanding that persons with cardiopulmonary disease would receive care from an NPAPP with autonomy to direct, manage, and prescribe respiratory therapy services, though not necessarily to prescribe medications. Sixty-eight percent $(n=954)$ of all respondents strongly agreed or somewhat agreed that a current need exists for an NPAPP, including $13.6 \%$ who strongly agreed, even with the prescribing limitation (Table 2). Physicians providing care to a larger number of cardiopulmonary disease patients and to a caseload of $>300$ patients/month were more likely to agree that a current need exists for an NPAPP (Table 3).
A chi-square test of independence was performed to examine the relationship between medical specialty and agreement that there is a current need for an NPAPP with cardiopulmonary expertise. The relationship between these variables was significant (chi-square test $=86.65, n=$ $1,401, P<.001)$. Physicians in the specialties of sleep $(91.5 \%, n=184)$, pulmonary $(75.0 \%, n=150)$, and critical care $(71.0 \%, n=142)$ were most likely to strongly agree or somewhat agree that a current need exists for an NPAPP with cardiopulmonary expertise. Anesthesiologists were less likely to express that a current need exists for an NPAPP $(53.5 \%, n=107)$ (Table 4). In addition, of the $13.6 \%$ of respondents who strongly agreed that a current need exists, pulmonologists $(n=42)$, critical care specialists $(n=40)$, and sleep specialists $(n=26)$ expressed the strongest agreement.

When considering the need for an NPAPP in the future, $74.4 \%(n=1,042)$ agreed, with $22.3 \%(n=313)$ indicating that they strongly agreed and $52.0 \%(n=729)$ indicating that they somewhat agreed. Similar to above, there is a significant relationship between medical specialty and agreement that there is a future need for an NPAPP with cardiopulmonary expertise. Sleep specialists $(91.0 \%, n=$ $183)$, pulmonologists $(83.5 \%, n=167)$, and critical care specialists $(77.0 \%, n=154)$ were more likely than other specialties to anticipate a future need for an NPAPP (chisquare test $=69.76, n=1,401, P<.001)($ Table 5). 


\section{Physician Support for Advanced Practice Providers}

Table 2. Respondents' Perception of NPAPP Impact

\begin{tabular}{|c|c|c|c|c|}
\hline & Strongly Agree & Somewhat Agree & Somewhat Disagree & Strongly Disagree \\
\hline $\begin{array}{l}\text { There is a current need for an NPAPP position to care for } \\
\text { patients with CPD. }\end{array}$ & $191(13.6)$ & $763(54.5)$ & $318(22.7)$ & $129(9.2)$ \\
\hline $\begin{array}{l}\text { Having an NPAPP on my care team would boost efficiency } \\
\text { and productivity in care for patients with CPD. }\end{array}$ & $374(26.7)$ & $657(46.9)$ & $254(18.1)$ & $116(8.3)$ \\
\hline $\begin{array}{l}\text { Having an NPAPP on my care team would improve the } \\
\text { experience for patients with CPD. }\end{array}$ & $304(21.7)$ & $713(50.9)$ & $273(19.5)$ & $111(7.9)$ \\
\hline $\begin{array}{l}\text { Having an NPAPP on my care team would provide } \\
\text { benefits other clinicians are not trained to provide for } \\
\text { patients with CPD. }\end{array}$ & $282(20.1)$ & $630(45.0)$ & $332(23.7)$ & $157(11.2)$ \\
\hline Caring for patients with CPD is becoming more complex. & $570(4.7)$ & $688(49.1)$ & $116(8.3)$ & $27(1.9)$ \\
\hline $\begin{array}{l}\text { Having an NPAPP on my care team would improve care } \\
\text { for patients with CPD. }\end{array}$ & $299(21.3)$ & $716(51.1)$ & $259(18.5)$ & $127(9.1)$ \\
\hline \multicolumn{5}{|l|}{$\begin{array}{l}\text { Adding an NPAPP specializing in the care of CPD } \\
\text { patients would }\end{array}$} \\
\hline Improve patient experiences & $333(23.8)$ & $729(52.0)$ & $235(16.8)$ & $104(7.4)$ \\
\hline Improve patient outcomes & $244(17.4)$ & $695(49.6)$ & $325(23.2)$ & $137(9.8)$ \\
\hline $\begin{array}{l}\text { I would benefit from having an NPAPP specializing in the } \\
\text { care of CPD patients join my care team. }\end{array}$ & $283(20.2)$ & $711(50.8)$ & $299(21.3)$ & $108(7.7)$ \\
\hline $\begin{array}{l}\text { Data are presented as } n(\%) . \\
\text { NPAPP = non-physician advanced care provider } \\
\text { CPD }=\text { cardiopulmonary disease }\end{array}$ & & & & \\
\hline
\end{tabular}

Table 3. Perception of Current Need for an NPAPP With CPD Expertise by Caseload

\begin{tabular}{|c|c|c|c|c|}
\hline $\begin{array}{l}\text { There is a current need for an NPAPP } \\
\text { position to care for patients with CPD }\end{array}$ & Strongly Agree & Somewhat Agree & Somewhat Disagree & Strongly Disagree \\
\hline \multicolumn{5}{|l|}{$\%$ of patients with CPD } \\
\hline$<20 \%$ & 0 & 0 & 0 & 0 \\
\hline $20-39 \%$ & $58(11.0)$ & $266(50.8)$ & $140(26.7)$ & $60(11.5)$ \\
\hline $40-59 \%$ & $45(11.6)$ & $228(58.8)$ & $87(22.4)$ & $28(7.2)$ \\
\hline $60-79 \%$ & $35(12.8)$ & $153(56.0)$ & $54(19.8)$ & $31(11.4)$ \\
\hline $80-100 \%$ & $53(24.5)$ & $116(53.7)$ & $37(17.1)$ & $10(4.7)$ \\
\hline Total & 191 & 763 & 318 & 129 \\
\hline \multicolumn{5}{|l|}{ Patients treated in 1 month } \\
\hline$<150$ & $38(11.1)$ & $165(48.3)$ & $100(29.2)$ & $39(11.4)$ \\
\hline $150-300$ & $83(13.1)$ & $371(58.6)$ & $127(20.1)$ & $52(8.2)$ \\
\hline $301+$ & $70(16.4)$ & $227(53.3)$ & $91(21.4)$ & $38(8.9)$ \\
\hline Total & 191 & 763 & 318 & 129 \\
\hline \multicolumn{5}{|l|}{$\begin{array}{l}\overline{\text { Data are presented as } n}(\%) . \\
\text { NPAPP = non-physician advanced care provider } \\
\mathrm{CPD}=\text { cardiopulmonary disease }\end{array}$} \\
\hline
\end{tabular}

The next section asked whether physicians agreed or disagreed that an NPAPP specializing in the care of cardiopulmonary disease would improve patient experience and patient outcomes, and that there is a future need for an NPAPP position to care for patients with cardiopulmonary disease. A majority (75.8\%) of the physicians strongly agreed or somewhat agreed that a future need existed for an NPAPP position to allow for improvement in the patient experience and to improve patient outcomes (Table 2).

\section{Workforce Gap Location}

To further inform the results regarding the need for an NPAPP specializing in the care of persons with cardiopulmonary disease, responses were stratified based on practice setting (in-patient only, out-patient only, or both in-patient and out-patient) and on geographic location using the 10 regions demarcated by the U.S. Department of Health and Human Services. Respondents were relatively evenly 


\section{Physician Support for Advanced Practice Providers}

Table 4. Current Need for an NPAPP With Cardiopulmonary Disease Expertise by Medical Specialty

\begin{tabular}{lccc}
\hline \hline \multicolumn{1}{c}{ Medical Specialty } & Agree & Disagree & Total \\
\hline Sleep specialist & $184(91.5)$ & $17(8.5)$ & 201 \\
Pulmonology & $150(75.0)$ & $50(25.0)$ & 200 \\
Critical care & $142(71.0)$ & $58(29.0)$ & 200 \\
Allergy and immunology & $126(63.0)$ & $74(37.0)$ & 200 \\
Pediatrics & $245(61.2)$ & $155(38.8)$ & 400 \\
Anesthesiology & $107(53.5)$ & $93(46.5)$ & 200 \\
Total & 954 & 447 & 1,401
\end{tabular}

Data are presented as $n(\%)$. Chi-square test $=86.65(N=1,401, P<.001)$

NPAPP $=$ non-physician advanced care provider

Table 5. Future Need for an NPAPP With Cardiopulmonary Disease Expertise by Medical Specialty

\begin{tabular}{lccc}
\hline \hline \multicolumn{1}{c}{ Medical Specialty } & Agree & Disagree & Total \\
\hline Sleep specialist & $183(91.0)$ & $18(9.0)$ & 201 \\
Pulmonology & $167(83.5)$ & $33(16.5)$ & 200 \\
Critical care & $154(77.0)$ & $46(23.0)$ & 200 \\
Allergy and immunology & $142(71.0)$ & $58(29.0)$ & 200 \\
Pediatrics & $278(69.5)$ & $122(30.5)$ & 400 \\
Anesthesiology & $118(59.0)$ & $82(41.0)$ & 200 \\
Total & 1042 & 359 & 1,401
\end{tabular}

$\overline{\text { Data are presented as } n}(\%)$. Chi-square test $=69.76(N=1,401, P<.001)$.

NPAPP $=$ non-physician advanced care provider

Table 6. Current Need for an NPAPP With Cardiopulmonary Disease Expertise by Practice Setting

\begin{tabular}{lccc}
\hline \hline \multicolumn{1}{c}{ Practice Setting } & Agree & Disagree & Total \\
\hline In-patient & $280(69.7)$ & $122(30.3)$ & 402 \\
Out-patient & $351(67.2)$ & $171(32.8)$ & 522 \\
Both in-patient and out-patient & $323(67.7)$ & $154(32.3)$ & 477 \\
Total & 954 & 447 & 1,401 \\
& & & \\
Data are presented as $n$ (\%). Chi-square test $=0.655(N=1,401, P=.72)$. & \\
NPAPP = non-physician advanced care provider & \\
\end{tabular}

distributed across all 3 categories of practice setting (Table 1), whereas several geographic regions were somewhat underrepresented (Figure 1). As a result, chi-square tests of independence were only conducted to analyze the relationship between practice setting and agreement that there is a current and future need for an NPAPP with cardiopulmonary expertise. The proportion of respondents who reported agreement that there is a current need for an NPAPP with cardiopulmonary expertise did not differ by practice setting (chi-square test $=0.655, N=1,401, P=.72$ ) (Table 6). Additional analysis of responses regarding a future need found similar results, indicating that there was no
Table 7. Future Need for an NPAPP With Cardiopulmonary Disease Expertise by Practice Setting

\begin{tabular}{lccc}
\hline \hline \multicolumn{1}{c}{ Practice Setting } & Agree & Disagree & Total \\
\hline In-patient & $308(76.6)$ & $94(23.4)$ & 402 \\
Out-patient & $389(74.5)$ & $133(25.5)$ & 522 \\
Both in-patient and out-patient & $345(72.3)$ & $132(27.7)$ & 477 \\
Total & 1,042 & 359 & 1,401 \\
& & \\
Data are presented as $n(\%)$. Chi-square test $=2.12(N=1,401, P=.35)$. & \\
NPAPP = non-physician advanced care provider & \\
\hline
\end{tabular}

significant association between practice setting and agreement that there will be a future need for an NPAPP (chisquare test $=2.12, N=1,401, P=.35$ (Table 7).

Respondents were asked to indicate how helpful an NPAPP would be in their clinical setting. Of physicians practicing in in-patient only settings, 69.7\% $(n=280)$ strongly agreed or somewhat agreed that it would be helpful to include this practitioner when providing care to patients with cardiopulmonary disease; similarly, $67.2 \%(n=351)$ of physicians practicing in out-patient only settings and $67.7 \%(n=323)$ of physicians practicing in settings with both in-patients and out-patients strongly agreed or somewhat agreed that it would be helpful to include this practitioner when providing care to patients with cardiopulmonary disease (Appendix B; see the supplementary materials at http://www.rcjournal.com). An openended question prompted physicians to provide reasons for their response. These reasons were coded and grouped into categories. The most common reasons given by those providing in-patient only care included better care with improved outcomes, specialized expertise, and increased follow-up care, including ordering diagnostics and therapeutics. Physicians working only in out-patient settings indicated similar reasons as well as improved patient education and assistance with managing patient work load as explanations for their ratings. The only additional reason added by physicians who practice in both the in-patient and the out-patient settings was providing extra support to the physician.

When asked directly if they would benefit from an NPAPP specializing in the care of patients with cardiopulmonary disease joining their care team, $71.0 \%(n=994)$ of physicians across all practice settings indicated that they strongly agreed or somewhat agreed (Table 2). Respondents were also asked to evaluate their interest in hiring an NPAPP if they had the authority and the budget to do so. Physicians who practice in both in-patient and outpatient settings $(72.4 \%, n=345)$ or practice only in inpatient settings $(73.4 \%, n=295)$ indicated interest in hiring an NPAPP, while $67.8 \%(n=354)$ of physicians working only in out-patient settings indicated an interest. The reasons identified for their interest in hiring an NPAPP 
Physician Support for Advanced Practice Providers

Table 8. Interest in Hiring an NPAPP in 1-2 y Assuming No Hiring Barriers by Medical Specialty

\begin{tabular}{|c|c|c|c|c|c|}
\hline Medical Specialty & Very Interested & Somewhat Interested & Just a Little Interested & Not at all Interested & Total \\
\hline Sleep specialist & $39(19.4)$ & $138(68.6)$ & $16(8.0)$ & $8(4.0)$ & 201 \\
\hline Pulmonology & $73(36.5)$ & $82(41.0)$ & $26(13.0)$ & $19(9.5)$ & 200 \\
\hline Critical care & $81(40.5)$ & $63(31.5)$ & $31(15.5)$ & $25(12.5)$ & 200 \\
\hline Allergy and immunology & $44(22.0)$ & $66(33.0)$ & $48(24.0)$ & $42(21.0)$ & 200 \\
\hline Pediatrics & $77(19.2)$ & $140(35.0)$ & $93(23.3)$ & $90(22.5)$ & 400 \\
\hline Anesthesiology & $27(13.5)$ & $67(33.5)$ & $55(27.5)$ & $51(25.5)$ & 200 \\
\hline Total & 341 & 556 & 269 & 235 & 1,401 \\
\hline
\end{tabular}

mirrored the reasons they indicated for why an NPAPP would be helpful in their clinical setting.

The survey revealed some regional differences in perceptions. In most regions, $>70 \%$ of respondents agreed there would be a future need for an NPAPP, although $58 \%$ of respondents from Region 10 agreed. All regions demonstrated a majority of agreement when asked if having an NPAPP on their care team would boost efficiency and productivity when providing care, would improve the patient experience, and would improve care for patients with cardiopulmonary disease. A majority also responded in agreement with the statement that an NPAPP would provide benefits other clinicians are not trained to provide for persons with cardiopulmonary disease, though less strongly in Regions 8 and 10 (Appendix C; see the supplementary materials at http:// www.rcjournal.com). Comparatively, respondents in Region 9 responded most favorably overall, and respondents in Region 10 responded least favorably overall.

\section{Hiring an NPAPP}

To gauge the interest and market potential for the utilization of an NPAPP, one of the study questions prompted respondents to presume a reimbursement mechanism is in place for NPAPPs with cardiopulmonary expertise, and that they had the authority and the budget to hire NPAPPs. The study referred to this hypothetical situation as a "magic wand" scenario. Using a magic wand scenario to remove hiring barriers revealed a similar demand for the NPAPP. Responses showed $64.0 \%(n=897)$ of responding physicians had an interest in hiring this specialized professional within the next $1-2$ y (with $24.3 \%$ indicating "very interested"). Sleep specialists, pulmonology, and critical care clinicians were most interested in hiring an NPAPP under magic wand conditions (Table 8).

Physicians completing the survey were also asked to determine the importance of several factors when thinking about the potential need to hire an NPAPP. Lack of time to spend with patients, increasing complexity of patient care, lack of time for non-patient care tasks like care coordination, lack of reimbursement for respiratory therapy services, and lack of physician specialists in the area were all rated as very important or somewhat important by a majority of respondents. Lack of access to respiratory therapists and a lack of autonomy in current respiratory therapy roles were rated as very important or somewhat important by $60.4 \%$ $(n=846)$ and $57 \%(n=801)$ of physicians, respectively (Appendix D; see the supplementary materials at http:// www.rcjournal.com). Respondents were asked to specify how adding an NPAPP to their practice would affect the number of patients the practice was able to serve.

At the conclusion of the survey, physicians were asked about potential benefits of adding an NPAPP to their practice without changing the number of physicians. Spending more time with complex patients was the most important benefit noted, with $76.7 \%$ ( $n=1,074)$ of physicians across all practice settings strongly agreeing or somewhat agreeing. Both spending more time with individual patients and seeing more patients overall were believed to be benefits, with $71.6 \%$ ( $n=1,004)$ and $69 \%(n=966)$ agreement, respectively, among physicians in all clinical settings. Sixty-one percent $(n=856)$ strongly agreed or somewhat agreed that adding an NPAPP to their practice would allow them to provide care that they would not be able to provide otherwise (Table 9).

\section{Perceived Impact of an NPAPP Position}

Physicians were asked to reflect on the current care provided and how an NPAPP specializing in the care of persons with cardiopulmonary disease could impact current practice. Of those surveyed, $89.8 \%$ agreed that caring for patients with cardiopulmonary disease is becoming more complex, and $73.6 \%$ of respondents indicated that a specialized NPAPP would boost efficiency and productivity in the care of patients with cardiopulmonary disease. In addition to improving efficiency and productivity, a majority of respondents also perceived that having a specialized 


\section{Physician Support for Advanced Practice Providers}

Table 9. Perceived Impact of NPAPP on Clinical Work Load

\begin{tabular}{|c|c|c|c|c|}
\hline $\begin{array}{c}\text { Finally, assuming the number of doctors in your practice } \\
\text { does not change, would adding an NPAPP position to } \\
\text { your staff allow you to ... }\end{array}$ & Strongly Agree & Somewhat Agree & Somewhat Disagree & Strongly Disagree \\
\hline See more patients overall? & $299(21.3)$ & $667(47.6)$ & $299(21.3)$ & $136(9.8)$ \\
\hline Spend more time with individual patients? & $325(23.2)$ & $679(48.4)$ & $277(19.8)$ & $120(8.6)$ \\
\hline Provide care you would not be able to provide otherwise? & $221(15.8)$ & $635(45.3)$ & $347(24.8)$ & $198(14.1)$ \\
\hline Spend more time with complex patients? & $422(30.1)$ & $652(46.5)$ & $204(14.6)$ & $123(8.8)$ \\
\hline
\end{tabular}

Table 10. Physician Perception of Factors Influencing the Need for an NPAPP Specializing in the Care of Patients With CPD

\begin{tabular}{|c|c|c|c|c|}
\hline $\begin{array}{l}\text { How important are the following factors when thinking } \\
\text { about the potential need to hire an NPAPP specializing in } \\
\text { the care of patients with CPD? }\end{array}$ & Very Important & Somewhat Important & Just a Little Important & Not at All Important \\
\hline Lack of time to spend with patients & $547(39.1)$ & $537(38.3)$ & $201(14.3)$ & $116(8.3)$ \\
\hline Increasing complexity of patient care & $510(36.4)$ & $563(40.2)$ & $196(14.0)$ & $132(9.4)$ \\
\hline $\begin{array}{l}\text { Lack of time for important tasks that do not directly } \\
\text { involve seeing patients (eg, administrative tasks, care } \\
\text { coordination tasks) }\end{array}$ & $417(29.8)$ & $609(43.4)$ & $256(18.3)$ & $119(8.5)$ \\
\hline Lack of reimbursement for RT services & 419 (29.9) & $578(41.2)$ & $239(17.1)$ & $165(11.8)$ \\
\hline Lack of physician specialists in the area & $290(20.7)$ & $501(35.7)$ & $301(21.5)$ & $309(22.1)$ \\
\hline Lack of access to RTs & $245(17.5)$ & $601(42.9)$ & $311(22.2)$ & $244(17.4)$ \\
\hline Lack of autonomy of the RTs in their current roles & $178(12.7)$ & $623(44.5)$ & $354(25.3)$ & $246(17.5)$ \\
\hline $\begin{array}{l}\text { Data are presented as } n(\%) . \\
\text { NPAPP = non-physician advanced care provider } \\
\text { CPD }=\text { cardiopulmonary disease } \\
\text { RT }=\text { respiratory therapist }\end{array}$ & & & & \\
\hline
\end{tabular}

NPAPP on the care team would improve the care for patients with cardiopulmonary disease $(72.4 \%)$ and provide benefits that other clinicians are not trained to provide for this patient population $(65.1 \%)$. Overall, physicians perceived that adding an NPAPP specializing in the care of patients with cardiopulmonary disease could improve patient experience (75.8\%) and improve patient outcomes (67.0\%) (Table 2).

Physicians were also asked to consider factors that would influence the need for an NPAPP specializing in the care of patients with cardiopulmonary disease. Factors that were ranked either very important or somewhat important were lack of time to spend with patients $(77.4 \%)$, increasing complexity of patient care (76.6\%), and lack of time for important tasks that do not directly involve seeing patients, such as administrative and care coordination tasks (73.2\%). Factors such as lack of physician specialists in the geographic area $(56.4 \%)$ were perceived as less important in the determination of need for an NPAPP (Table 10). The results also indicate that, when provided with a scale from 0 (absolutely disagree) to 10 (absolutely agree), physicians were more positive about the impact of a specialized NPAPP on quality of care than the financial assistance provided to the practice (Table 11).

\section{Discussion}

Our survey results indicate that most physicians expressed a certain interest in the proposed NPAPP position. Agreeing that caring for persons with cardiopulmonary disease is becoming increasingly more complex, more than two thirds of physician respondents expressed both a current $(68.1 \%)$ and future $(74.4 \%)$ need for an NPAPP. This study also revealed remarkably similar perceptions regarding the need, role, and benefit of the proposed NPAPP across specialties, practice settings, and geographic locations.

These responses echo findings in the literature that point to both current and future gaps in the workforce by identifying poor physician coverage for critical care areas, ${ }^{6}$ long wait times for routine office visits, ${ }^{7}$ and difficulty recruiting physicians and NPAPPs with specialized training for persons with cardiopulmonary disease. ${ }^{7-9}$ Analysis of the 
Physician Support for Advanced Practice Providers

Table 11. Physician Perspective on the Implications of Integrating an NPAPP Specializing in the Care of Patients With CPD

\begin{tabular}{lcc}
\hline \hline & Positive & Neutral \\
\hline $\begin{array}{l}\text { From a clinical perspective, the creation of an NPAPP position to } \\
\text { care for patients with CPD would improve the quality of care. }\end{array}$ & $797(56.9)$ & 181 (12.9) \\
$\begin{array}{l}\text { From a financial perspective, the creation of an NPAPP position to } \\
\text { care for patients with CPD would help my practice. }\end{array}$ & $573(40.9)$ & 247 (17.6) \\
$\begin{array}{l}\text { Data are presented as } n \text { (\%). On a scale of } 0-10,6-10=\text { Positive, } 5=\text { Neutral, and } 0-4=\text { Negative. } \\
\text { NPAPP = non-physician advanced care provider } \\
\text { CPD = cardiopulmonary disease }\end{array}$ & \\
\hline
\end{tabular}

literature demonstrates a more pronounced need in specialty areas such as sleep medicine ${ }^{4}$ and out-patient chronic pulmonary clinics $^{7}$ (eg, cystic fibrosis) in addition to inadequate coverage in critical care, ${ }^{10,11}$ which correlates with the findings of this study.

The scope of the workforce gap is revealed in the discovery that the majority of respondents $(65.1 \%)$ believe that an NPAPP would provide benefits that other clinicians are not trained to provide for persons with cardiopulmonary disease. In addition, those physicians who treat a higher percentage (ie, $60 \%$ or more) of persons with cardiopulmonary disease perceive a greater need for this proposed provider. The literature reports that the integration of NPAPPs into various practice settings has improved quality of patient care, increased scheduling flexibility, improved coordination of care, and allowed for expansion of services. ${ }^{7,12}$

In 2015, Evans and Landen ${ }^{13}$ purported that a fast-growing economy and fewer uninsured individuals would expand employment in the health care sector. This trend continues today, but there remain no assurances an NPAPP will be hired as part of the growth in the health care workforce. There are many barriers in the marketplace supporting this argument (eg, training and education, scope of practice, practice setting), but these findings support the need to develop a mechanism to reimburse for the services an NPAPP with cardiopulmonary expertise would provide. Currently, reimbursement for the direct care and services provided by an NPAPP specializing in the care of patients with cardiopulmonary disease does not exist.

The lack of a trained workforce, both physicians and NPAPPs, is antithetic to the tenets of value-based care: lower costs, improved patient outcomes, and improving the patient's experience. ${ }^{14-16}$ Utilization of a properly trained NPAPP to provide care for persons with cardiopulmonary disease, particularly those with low to moderate risk, supports improved outcomes at less cost and improves both the patient and clinician experience. In a discussion of the need for more ICU intensivist physicians, Kahn and Rubenfeld ${ }^{11}$ offered several suggestions to improve quality outcomes, one being the use of "interprofessional care models driven by non-physician providers . . . to be used to deliver care for ICU patients with low illness severity." The literature findings support that the most common reason for ICU admission is respiratory insufficiency. ${ }^{10}$ Given the literature and this study's results, it is paramount to consider a mechanism supporting the use of NPAPP trained to deliver care to persons with cardiopulmonary disease. ${ }^{11,17}$ Considering the respondents' strong confidence in the current role of the respiratory therapist, it is logical to build on the respiratory therapist's specialized foundation of knowledge and patient care when developing an NPAPP with cardiopulmonary expertise.

\section{Future Considerations}

There are many challenges ahead that will need to be solved before an NPAPP becomes a reality. For example, there is a need for educational programs at the master's degree level that can provide the instruction and clinical training required to assume a role as a physician extender. A certification process to recognize a consistent and a competent skill set, state licensure laws and practice acts to approve, and an integration process into health care systems are needed. Lastly, studies are needed to identify areas requiring additional work that are not currently foreseen as health care continues to expand and change.

\section{Limitations}

Although the $100 \%$ response rate of the target audience was guaranteed through the study design, this study does have limitations. Participants may not provide truthful responses, respondents had to select from predetermined response categories, and respondents may have experienced fatigue due to the length of the survey despite being informed that the survey would only take 10-15 $\mathrm{min}$ to complete. The sleep specialists who completed the survey by telephone may have been affected by the complexity of listening to multifaceted questions and impatience with the survey responses. Furthermore, regarding the proposed NPAPP with cardiopulmonary expertise, the respondents did not have details about educational preparation, academic curriculum, or business models to incorporate the proposed role. Because the survey eliminated complex barriers such as authority, budget, and reimbursement (ie, the 


\section{Physician Support for Advanced Practice Providers}

"magic wand" scenario), the actual impact of implementing the proposed role may differ from survey responses.

\section{Conclusions}

Physicians within the practices of allergy and immunology, anesthesiology, critical care, pediatrics, pulmonology, and sleep medicine agree that there is a need for an NPAPP who specializes in the care of persons with cardiopulmonary disease and would likely hire them. Given the confidence that physicians have in respiratory therapists currently on their care teams, developing the NPAPP concept to include building on the specialized knowledge and skills of respiratory therapists should be considered. An NPAPP with this formal education and training may help reduce costs of health care, eliminate a perceived gap in providing care, and improve quality of care, patient experience, and health care outcomes. Additional research is required to determine whether the inclusion of an NPAPP with cardiopulmonary disease expertise would meet the perceived need and improve efficiency of physician practices. Given providers' and patients' increased acceptance of an NPAPP caring for patients across many specialty areas, it is time to introduce the role of an NPAPP into the routine care of patients with cardiopulmonary disease.

\section{REFERENCES}

1. Association of American Medical Colleges. New findings confirm predictions on physician shortage. Available at: https://www.aamc.org/newsinsights/press-releases/new-findings-confirm-predictions-physicianshortage. Accessed June 21, 2019.

2. Hooker RS, Muchow AN. Modifying state laws for nurse practitioners and physician assistants can reduce cost of medical services. Nurs Econ 2015;33(2):88-94.

3. Dall T, Chakrabarti R, Lacobucci W, Hansari A, West T. 2017 Update: The complexities of physician supply and demand: Projections from 2015 to 2030: Final Report. doi: CrossRef.
4. U.S. Department of Health and Human Services. Regional offices. Available at: https://www.hhs.gov/about/agencies/iea/regional-offices/ index.html. Accessed June 21, 2019.

5. U.S. Census Bureau. Decennial census of population and housing. Decennial census datasets. Available at: https://www.census.gov/ programs-surveys/decennial-census/data/datasets.2010.html. Accessed June 21, 2019

6. Aseltine RH, Katz MC, Geragosian AH. Connecticut 2009 primary care survey: physician satisfaction, physician supply and patient access to medical care. Conn Med 2010;74(5):281-291.

7. Brown RF, Willey-Courand DB, George C, McMullen A, Dunitz J, Slovis B, et al. Non-physician providers as clinical providers in cystic fibrosis: survey of U.S. programs. Pediatr Pulmonol 2013;48(4):398404.

8. Watson NF, Rosen IM, Chervin RD, Board of Directors of the American Academy of Sleep Medicine. The past is prologue: the future of sleep medicine. J Clin Sleep Med 2017;13(1):127-135.

9. Colvin L, Cartwright A, Collop N, Freedman N, McLeod D, Weaver TE, et al. Advanced practice registered nurses and physician assistants in sleep centers and clinics: a survey of current roles and educational background. J Clin Sleep Med 2014;10(5):581-587.

10. Angus DC, Shorr AF, White A, Dremsizov TT, Schmitz RJ, Kelley MA, et al. Critical care delivery in the United States: distribution of services and compliance with Leapfrog recommendations. Crit Care Med 2006;34(4):1016-1024.

11. Kahn JM, Rubenfeld GD. The myth of the workforce crisis. Why the United States does not need more intensivist physicians. Am J Respir Crit Care Med 2015;191(2):128-134.

12. Dies N, Rashid S, Shandling M, Swallow C, Easson AM, Kennedy E. Physician assistants reduce resident workload and improve care in an academic surgical setting. JAAPA 2016;29(2):41-46.

13. Evans M, Landen R. Hiring in healthcare will improve, but boom will bypass hospitals. Mod Healthc 2015;45(3):8-9.

14. Porter ME. What is value in health care? N Engl J Med 2010;363 (26):2477-2481.

15. Porter ME. A strategy for health care reform - toward a value-based system. N Engl J Med 2009;361(2):109-112.

16. Burwell SM. Setting value-based payment goals - HHS efforts to improve U.S. health care. N Engl J Med 2015;372(10):897-899.

17. Joyner RL, Strickland SL, Becker EA, Ginier E, Keene S, Rye K, Haas CF. Adequacy of the provider workforce for persons with cardiopulmonary disease. Chest 2020;157(5):1221-1229. 